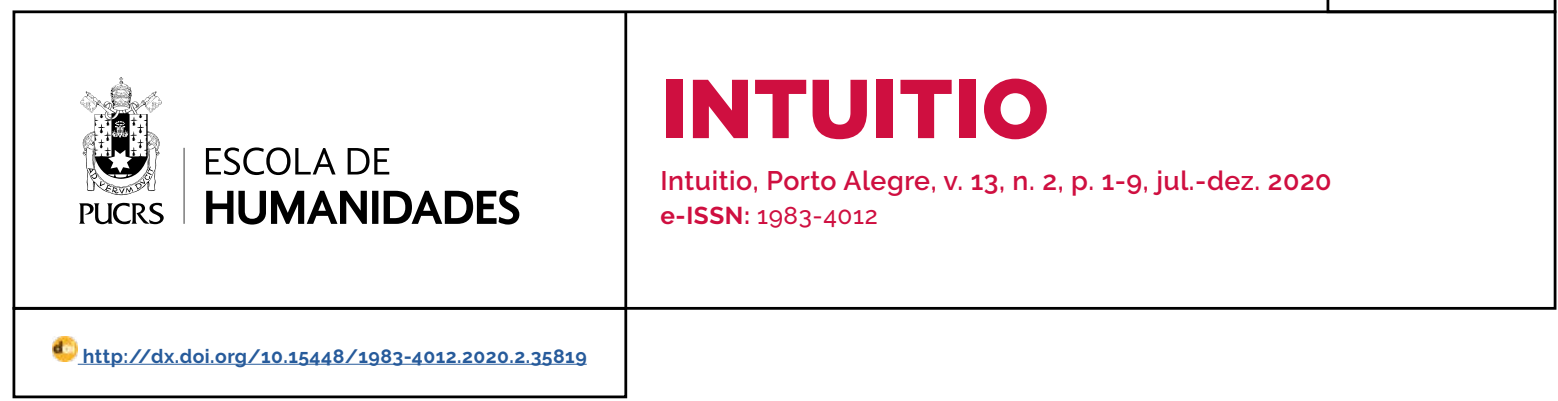

SEÇÃO: ARTIGO

\title{
DE QUE E DE QUEM EXATAMENTE NÓS FALAMOS QUANDO FALAMOS DOS ANIMAIS?
}

\author{
Who and what are we talking about when we talk about animals?
}

\section{Thiago Vinicius \\ Rodrigues de \\ Vasconcelos ${ }^{1}$}

orcid.org/0000-0002-7048-5205

thiagov.rvasconcelos@gmail.com

Enviado em: 30/9/2019

Aprovado em: 8/9/2020

Publicado em: 19/2/2021

\section{(c) (1)}

Artigo está licenciado sob forma de uma licença Creative Commons Atribuição 4.0 Internacional.

\begin{abstract}
Resumo: Este trabalho tem como objetivo analisar a reflexão de Hans Jonas acerca do estatuto ontológico do animal que está inserida, neste contexto, em uma análise mais geral sobre o fenômeno da vida e se apresenta como um momento importante na ontologia que pretende combater o dualismo e a ruptura entre animais humanos e não humanos. Ao reconhecer graus diferenciados de atividade espiritual entre os seres vivos, o autor, contudo, não partilha a ideia de uma igualdade plena entre os animais, embora sua perspectiva parta de traços comuns que acentuam a transanimalidade do homem, ou seja, o seu pertencimento e, ao mesmo tempo, a sua diferença em relação às alimárias. Por isso, sua filosofia não se limita ao discurso sobre os direitos animais, mas, antes, pretende pensar uma nova ontologia animal e uma nova animalidade humana a partir da integridade psicofísica e da relação constitutiva dos animais humanos e não humanos no âmbito da natureza.

Palavras-chave: Animal. Animalidade. Hans Jonas.
\end{abstract}

Abstract: This work aims to analyze the Hans Jonas' reflection on the ontological status of the animal that is inserted, in this context, in a more general analysis of the phenomenon of life and presents itself as an important topic in the ontology that intends to combat dualism and the rupture between human animals and non-human animals. By recognizing different degrees of a spiritual activity among living beings, the author, however, does not share the idea of a full equality among animals, although his perspective is of common traits that accentuate the trans animality of man, that is, its belonging and, at the same time, its difference in relation to the beasts. Therefore, his philosophy is not limited to the discourse on animal rights, but rather intends to think of a new animal ontology and a new human animality through the psychophysical integrity and the constitutive relationship between human and non-human animals within the field of nature. Keywords: Animal. Animality. Hans Jonas.

\section{Introdução}

A filosofia ocidental é marcada pela tensão fundamental entre o ser humano e o ser animal, boa parte dela constituindo-se em um esforço para separar as duas coisas e, no caso humano, vencer a herança de sua própria animalidade. Afinal, a partir do século XIX, com a ascensão da teoria evolucionista e, mais tarde, por meio da biologia molecular, das ciências cognitivas, da primatologia e da paleoantropologia reconhece-se uma especificidade humana que não pode, ao mesmo tempo, 
desconsiderar o fato de que o ser humano traz consigo um passado animal. ${ }^{2}$

Ao esboçar uma tentativa de superação ontológica do dualismo, Hans Jonas recoloca o problema da relação entre o humano e o extra-humano a partir de uma "releitura do texto biológico"3 que assume dois aspectos: por um lado, "o autor mostra os limites do dualismo psicofísico e, por outro lado, procede a uma redefinição da especificidade do ser humano colocando-o em relação fecunda com o mundo natural vivente".4

Em sua biologia filosófica Hans Jonas se opõe à perspectiva que defende a existência de uma separação ontológica entre nós e o resto da natureza vivente a fim de reconhecer que a dimensão interior da vida, por estar presente no ser humano, só pode derivar das formas de existência orgânica que o precedem, "mesmo em suas estruturas mais primitivas o orgânico já prefigura o espiritual, e mesmo em suas dimensões mais elevadas o espirito permanece parte do orgânico". ${ }^{5}$ As considerações de Jonas buscam, neste sentido, derrubar as barreiras antropocêntricas da filosofia e da ciência moderna para que se manifeste "a verdadeira linha divisória entre o animal e o ser humano".6

\section{Pensar o animal}

A questão animal tem lugar na fenomenologia da vida como o elo intermediário entre a aparição da vida em geral e do ser humano em particular. O termo elo intermediário quer aqui evidenciar que a hermenêutica do vivente pelo vivente levada a cabo por Jonas destaca a continuidade ontológica no seio da natureza.
Nathalie Frogneux, a fim de evitar objeções quanto à utilização do termo animal na filosofia de Jonas, coloca a seguinte questão: "De que e de quem exatamente nós falamos quando falamos dos animais?".7 Objeção que Jacques Derrida expõe em o animal que logo sou e à qual, de acordo com Frogneux, Jonas não é indiferente:

Para além da borda pretensamente humana, para além dela mas de forma alguma sobre uma única borda oposta, no lugar do "Animal" ou da "Vida-Animal", há, de antemão, uma multiplicidade heterogênea de viventes, mais precisamente (pois dizer "viventes" é já dizer muito ou quase nada) uma multiplicidade de organizações das relações entre o vivente e a morte, das relações de organização e de não-organização entre os reinos cada vez mais difíceis a dissociar nas figuras do orgânico e do inorgânico, da vida e/ou da morte. Ao mesmo tempo intimas e abissais, essas relações não são jamais totalmente objetiváveis. Elas não permitem nenhuma exterioridade simples de um termo em relação ao outro. Segue-se dai que jamais se terá o direito de tomar os animais por espécies de um gênero que se nomearia $O$ Animal, o animal em geral. Cada vez que "se" diz "O Animal", cada vez que o filósofo, ou qualquer outro, diz no singular e sem mais "O Animal", pretendendo designar assim todo vivente que não seria o homem [...] diz uma bobagem. ${ }^{8}$

Para analisar esta questão a partir de Hans Jonas, voltemos a um texto escrito em 1967 e publicado posteriormente em seus Ensaios Filosóficos, no qual o autor se dedica à questão da delimitação do gnosticismo da Antiguidade Tardia, fazendo referência ao que chamará de 'síndrome gnóstica', algo que servirá de referência para pensarmos também a questão da animalidade. No texto de 1967 ele se vê frente ao problema dos critérios para delimitar de modo claro diferentes correntes e seitas como gnósticas.

\footnotetext{
2 Étienne Bimbenet, nas páginas iniciais de O animal que não sou mais (L'animal que je ne suis plus), faz uma comparação da pergunta por nossa origem animal com aquela que a filosofia fez sobre o enigma da morte: "A morte é algo que ninguém pode negar e que, entretanto, esquecemos; ela é este acontecimento irrefutável, mas mantido em silêncio; inevitável e, todavia, sempre evitado. A filosofia arma contra este imbróglio todos os seus recursos de clareza e de lucidez. No entanto, já é tempo que ela enfrente com esta mesma energia nosso passado animal (BIMBENET, Étienne. O animal que não sou mais. Tradução de Maurício José d'Escragnolle Cardoso. Curitiba: Ed. UFPR, 2014, p.17, grifo do autor).

3 JONAS, Hans. O principio vida: fundamentos para uma biologia filosófica. Tradução de Carlos Almeida Pereira. 2. ed. Petrópolis: Vozes, 2004, p. 7.

4 TIBALDEO, Roberto Franzini. "Animal, transanimal e humano no pensamento de Hans Jonas". In: CARVALHO, H. B. A. de; OLIVEIRA, J. (ed.). Ética, técnica e responsabilidade. Curitiba, PR: CRV; Teresina, PI: EDUFPI, 2015, p. 31.

5 JONAS, Hans. O principio vida: fundamentos para uma biologia filosófica. Tradução de Carlos Almeida Pereira. 2.ed. Petrópolis: Vozes, 2004, p. 11.

6 JONAS, Hans. O principio vida: fundamentos para uma biologia filosófica. Tradução de Carlos Almeida Pereira. 2.ed. Petrópolis: Vozes, 2004, p. 7 .

7 FROGNEUX, Nathalie. "Le syndrome animal chez Hans Jonas". In: BURGAT, Florence; CIOCAN, Cristian (ed.). Phénomenologie de la vie animale. Bucarest: Zeta Books, 2016, p. 233-234.

8 DERRIDA, J. O animal que logo sou. Tradução de Fábio. 2. ed. São Paulo: Editora Unesp. 2011, p. 60-61.
} 
Jonas constata a impossibilidade de definição de critérios precisos e claros para definir o pertencimento ao gnosticismo. Consequentemente, fará a opção por falar de uma síndrome ${ }^{9}$ gnóstica, enquanto múltiplos aspectos que permitem um diagnóstico prévio (mas não definitivo) do que é pertencer ao gnosticismo. Logo, é preciso uma "orelha musical" para reconhecer as condições de possibilidade do pertencimento ao gnosticismo.

No início de seu texto, originalmente apresentado no Colóquio Internacional sobre as Origens do Gnosticismo em abril de 1966 em Messina, Jonas, ao tematizar o gnosticismo, parece falar, na verdade, da dificuldade em definir a existência animal: ${ }^{10}$

Delimitar um fenômeno que é representado por uma diversidade de indivíduos [...] que consiste a se servir da unidade presumida dessa diversidade para the assinalar um nome genérico, em seguida se servir desse nome para definir a unidade dessa diversidade e decidir, por conseguinte, incluir tal ou tal individuo. ${ }^{11}$

O problema da delimitação do gnosticismo possibilita, por conseguinte, estabelecer chaves hermenêuticas da sua filosofia da existência animal. Qual sentido Jonas atribui ao termo "animal"? Ele tenta identificar, de acordo com Nathalie Frogneux, a "sindrome animal", ou seja, "seria possivel tomar o termo sindrome que ele adota para as correntes gnósticas e aplicá-lo à animalidade".12

Como estabelecer, então, a animalidade como uma característica específica entre a vida vegetal e a vida humana? Ora, a questão do ser animal aparece em Jonas como intermediário entre a aparição da vida e a aparição do ser humano, o que se dá em duas direções: a da continuidade ontológica mas, ao mesmo tempo, a da descontinuidade fenomenológica, já que a animalidade como forma vivente especifica, entre o vegetal e o humano, marca um limiar e um ganho para a liberdade no seio da natureza. ${ }^{13}$

É sobre o pano de fundo de uma continuidade entre os viventes que aparece a questão do aparecimento da vida animal, o que impossibilita identificar um critério único e preciso de distinção. Quando se trata do animal - assim como para o gnosticismo (dificilmente delimitado com nitidez) - "os critérios são fluidos e seria vão pretender que todos os critérios da animalidade fossem presentes em todos os individuos animais, nem que algum animal possa ser desprovido desses critérios". ${ }^{14}$ Nesse sentido, o que distingue a vida animal? Segundo Nathalie Frogneux

com a animalidade, è uma nova etapa na emer-
gência da liberdade, isto é, uma existência vi-
vente manifesta: essas são as características já
dispostas pelo conjunto de viventes infra-ani-
mais de maneira germinal e incipiente, que se
manifestam doravante. O animal faz aparecer a
insegurança da vida como ganho de uma forma
ulterior de liberdade. Essas características são
três: a mobilidade (Bewegungsfähigkeit), o sen-
timento (Gefühl) e a percepção (Wahrnehmung).
Três caracteristicas da sindrome animal, uma vez
que sua presença conjunta em um ser vivente
nos permite concluir que se trata de um animal.15

Aqui é preciso que Jonas adote uma estratégia

\footnotetext{
9 Sindrome significa um conjunto de signos, sintomas, modificações morfológicas, funcionais ou bioquímicas do organismo, de aparência às vezes dispar, mas formando uma entidade reconhecivel que, sem prever obrigatoriamente as causas dessas manifestações, permitem orientar o diagnóstico.

10 Hans Jonas já no prefácio de O fenômeno da vida demarca o distanciamento que sua biologia filosófica toma da analítica existencial de Heidegger. Ao afirmar que este livro oferece uma interpretação 'existencial' dos fatos biológicos Jonas se coloca contra a cisão entre vida e existência. Alguns exemplos de expressões que denotam a interpretação existencial dos fatos biológicos: "ao nos ocuparmos agora com a existência animal" (JONAS, Hans. O principio vida: fundamentos para uma biologia filosófica. Tradução de Carlos Almeida Pereira. 2.ed. Petrópolis: Vozes, 2004, p. 122, grifo nosso); "A liberdade na relação com a matéria, manifestada na existência metabólica da forma, necessariamente acarreta consigo a dependência da matéria" (JONAS, Hans. O principio vida: fundamentos para uma biologia filosófica. Tradução de Carlos Almeida Pereira. 2. ed. Petrópolis: Vozes, 2004, p. 122, grifo nosso); "A simultânea ocorrência de percepção e movimento inaugura um importante capitulo na história da liberdade, que teve início com a existência orgânica como tal, tendo-se expressado primeiramente na primordial inquietação metabolizante" (JONAS, Hans. O principio vida: fundamentos para uma biologia filosófica. Tradução de Carlos Almeida Pereira. 2.ed. Petrópolis: Vozes, 2004, p. 124, grifo nosso).

11 JONAS, Hans. Essais philosophiques: Du credo ancien à l'homme technologique. Édité par Damien Bazin et Olivier Depré; coordination scientifique et préface par Olivier Depré. Paris: Vrin, 2013, p. 263

12 FROGNEUX, Nathalie. Le syndrome animal chez Hans Jonas. In: BURGAT, Florence; CIOCAN, Cristian (ed.). Phénomenologie de la vie animale. Bucarest: Zeta Books, 2016, p. 235

13 FROGNEUX, Nathalie. Le syndrome animal chez Hans Jonas. In: BURGAT, Florence; CIOCAN, Cristian (ed.). Phénomenologie de la vie animale. Bucarest: Zeta Books, 2016, p. 235.

14 FROGNEUX, Nathalie. Le syndrome animal chez Hans Jonas. In: BURGAT, Florence; ClOCAN, Cristian (ed.). Phénomenologie de la vie animale. Bucarest: Zeta Books, 2016, p. 246-247.

${ }_{15}$ FROGNEUX, Nathalie. Le syndrome animal chez Hans Jonas. In: BURGAT, Florence; CIOCAN, Cristian (ed.). Phénomenologie de la vie animale. Bucarest: Zeta Books, 2016, p. 242-243.
} 
metodológica, já que uma forte objeção pode ser despertada: como ultrapassar o abismo aberto pela filosofia ao tomar o animal como "completamente outro, o completamente outro, mas que, em sua proximidade insuportável, não me sinto ainda com nenhum direito e nenhum título para chamá-lo meu próximo"? ${ }^{16}$ Como, então, conciliar o reconhecimento de uma proximidade entre humanos e animais sendo que os últimos são tomados como "uma coisa vista mas que não vê"17, isto é, como objeto, como assujeitado?

A questão que se coloca é a própria experiência humana do animal, já que por um lado, o ser humano não é mais um animal (o comportamento humano aparece distanciado dos comportamentos animais dos quais provém, embora, no caso de Jonas, ele seria uma espécie de complemento de grau) e, por outro lado, o ser humano foi e continua sendo um animal. Mas, qual é, então, a estratégia metodológica adotada por Jonas, evocada anteriormente, para enfrentar o paradoxo que é a interpretação do ser animal a partir da experiência do próprio ser humano?

Há três perspectivas de abordagem do ser animal, a saber, a perspectiva em terceira pessoa (a observação), a perspectiva em segunda pessoa (a empatia ${ }^{18}$ e, enfim, a perspectiva em primeira pessoa (a analogia ${ }^{19}$ ). ${ }^{20}$ A observação caracteriza a objetificação científica. Já a empatia significa o conhecimento imediato em segunda pessoa que repousa sobre uma intercorporeidade e que nos permite experimentar o que o outro experimenta enquanto vivente. E, por último, a analogia que diz respeito ao conhecimento da vida do qual dispõe todo vivente.

Os animais aproximaram-se de nós ao ser reconhecida nossa proveniência deles por descendência direta. Mas, dessa origem fala-se apenas por meio de um antropomorfismo, ou seja, utilizando-se o ser humano como medida para analisar o ser animal, dado que os animais seriam privados das características humanas, a saber, o Pensamento, a Razão, a Sociabilidade, a Técnica, "qualidades absolutas que fazem do homem, já de saída, um ser fora da natureza ou metafísico".21

A aproximação aos animais é, então, do mesmo modo, um distanciamento, uma vez que o ser animal é compreendido senão em relação ao ser humano e nunca "em si mesmo". De modo contrário, Jonas não pensa o antropomorfismo como uma pretensa superioridade da razão "como isolamento das demais condições e formas da vida"22, da qual os animais seriam simplesmente privados - como em Heidegger.

Por existir enquanto ser orgânico, isto é, por ser um corpo, o ser humano constitui um observador preparado por aquilo que ele é frente à manifestação do ser vivente. ${ }^{23}$ Afinal, para o autor, "a vida só pode ser conhecida pela vida". ${ }^{24}$ Nesse caso, é sendo animal em sua animalidade que o humano se torna, analogamente, capacitado para acessar a animalidade do animal em si mesma, como é o objetivo de qualquer fenomenologia.

\footnotetext{
16 DERRIDA, J. O animal que logo sou. Tradução de Fábio. 2. ed. São Paulo: Editora Unesp, 2011, p. 30.

17 DERRIDA, J. O animal que logo sou. Tradução de Fábio. 2. ed. São Paulo: Editora Unesp, 2011, p. 33.

18 "O gato levanta os olhos em direção a mim, ele busca meu olhar, ele quer alguma coisa de mim" (JONAS, Hans. Essais philosophiques: Du credo ancien à l'homme technologique. Édité par Damien Bazin et Olivier Depré; coordination scientifique et préface par Olivier Depré. Paris: Vrin, p. 246). Nessa passagem Jonas "vê o momento de reconhecimento mútuo entre um animal de companhia e um ser humano. Mas também o momento em que a vida é inevitavelmente expressiva e perceptiva, reversivel” (FROGNEUX, Nathalie. Le syndrome animal chez Hans Jonas. In: BURGAT, Florence; CIOCAN, Cristian (ed.). Phénomenologie de la vie animale. Bucarest: Zeta Books, 2016, p. 237). O gato buscar meu olhar comunica um vínculo mútuo.

19 Um puro espírito, um puro entendimento como potência matemática não poderia compreender a vida, uma vez que a existência orgânica com sua experiência própria é requisitada a fim de que seja capaz de operar a analogia.

20 FROGNEUX, Nathalie. Le syndrome animal chez Hans Jonas. In: BURGAT, Florence; ClOCAN, Cristian (ed.). Phénomenologie de la vie animale. Bucarest: Zeta Books, 2016, p. 235.

21 BIMBENET, Étienne. O animal que não sou mais. Tradução de Maurício José d'Escragnolle Cardoso. Curitiba: Ed. UFPR, 2014. p. 18.

22 OLIVEIRA, Jelson. A transanimalidade do homem: uma premissa do Principio Responsabilidade. In: SANTOS, R.; OLIVEIRA, J.; ZANCANARO, L. (ed.). Ética para a civilização tecnológica: em diálogo com Hans Jonas. São Paulo: Centro Universitário São Camilo, 2011, p. 48. 23 JONAS, Hans. O princípio vida: fundamentos para uma biologia filosófica. Tradução de Carlos Almeida Pereira. 2.ed. Petrópolis: Vozes, 2004, p. 105.

24 JONAS, Hans. O principio vida: fundamentos para uma biologia filosófica. Tradução de Carlos Almeida Pereira. 2.ed. Petrópolis: Vozes, 2004, p. 115
} 


\section{Liberdade animal ${ }^{25}$}

É no conceito de liberdade que Jonas encontra um "fio de Ariadne" capaz de nos orientar na tarefa de interpretação da vida. ${ }^{26}$ Mas, a liberdade não se reduz ao âmbito da racionalidade, antes ela é, para Jonas, uma característica que serve à descrição da estrutura mais elementar da vida. Há, por isso, na filosofia jonasiana, uma reinterpretação da noção de liberdade, uma vez que ela é um "traço ontológico fundamental da vida em si". ${ }^{27} \mathrm{~A}$ liberdade avança de seu princípio contínuo, desde a estrutura mais elementar da vida a graus mais elevados (ser humano), de uma liberdade inferior a uma liberdade superior, de uma liberdade mais simples a uma liberdade mais rica.

Este tema, comum a toda vida, buscaremos acompanhá-lo através do crescente desenvolvimento das capacidades e funções orgânicas: metabolismo, movimento e apetite, sensação e percepção, imaginação, arte e conceito, uma escala ascendente de liberdade e risco que culmina no ser humano. ${ }^{28}$

Animal e ser humano, como também as plantas $^{29}$, constituem, portanto, etapas do processo de evolução da vida, uma vez que a liberdade foi estendida a todo o reino do vivente. A vida em sua relação com o mundo manifesta-se em diferentes graus de liberdade, sendo que "quanto mais desligada, mais a vida se torna suscetivel aos perigos de sua própria extinção".30

A liberdade está relacionada no pensamento jonasiano com a percepção e com a ação. O autor se afasta das concepções que tomam esse conceito como algo que pertence unicamente ao terreno do espírito e da vontade e postula, consequentemente, que é possivel pensar a liberdade para além da dimensão do agir, a saber, também na dimensão do receber.

A liberdade significa não apenas a ação consciente em direção ao mundo, mas também a capacidade de se sentir afetado por ele. É essa afecção que torna possivel que a vida experimente - mesmo com os estímulos mais elementares de sensibilidade orgânica - "em germe de alteridade, o mundo e o objeto"31.

Neste sentido, a receptividade da sensibilidade, este lado passivo "põe a vida em condições de ser seletiva e de estar 'informada' em vez de ser puramente dinâmica cega".32 Ou seja, a liberdade por sua sensibilidade "opõe, então, o que será fonte de sofrimento e de gozo"33. Assim, além da necessidade orgânica da transcendência, a vida também é afetada desde fora na percepção do mundo exterior, de modo que "só pelo fato de que a vida é sensitiva pode ser também ativa"34.

A liberdade está fundada na fragilidade, precariedade e vulnerabilidade da vida. A atividade de intercâmbio metabólico entre organismo e mundo-ambiente constitui-se na abertura do ser ao mundo, uma abertura arriscada, perigosa e frágil, pois o ser está sempre ameaçado pelo não-ser: "A vida é orientada em direção ao mundo: é aberta à experiência, permanentemente em intercâmbio. A vida transcende a si mesma em direção ao seu outro, e isto é uma atividade

\footnotetext{
25 As ideias apresentadas neste tópico aparecem em um trabalho anterior (VASCONCELOS, Thiago. Existência em exilio: a questão do niilismo na filosofia de Hans Jonas. 2017. 176 f. Dissertação (Mestrado) - Pontificia Universidade Católica do Paraná, Curitiba, 2017).

26 JO JONAS, Hans. O principio vida: fundamentos para uma biologia filosófica. Tradução de Carlos Almeida Pereira. 2.ed. Petrópolis: Vozes, 2004, p. 14

27 JONAS, Hans. O principio vida: fundamentos para uma biologia filosófica. Tradução de Carlos Almeida Pereira. 2.ed. Petrópolis: Vozes 2004, p. 106.

28 JONAS, Hans. O principio vida: fundamentos para uma biologia filosófica. Tradução de Carlos Almeida Pereira. 2.ed. Petrópolis: Vozes, 2004, p. 8.

29 Emanuelle Coccia em La vie des plantes: une metáphysique du mélange analisa as plantas como objeto filosófico e, consequentemente, apresenta uma ontologia das plantas evidenciando-as como a condição de possibilidade para o aparecimento dos demais seres vivos, uma vez que são as plantas que produzem o ambiente - ao produzir biomassa, isto é, matéria vivente transformando, desse modo, matéria inorgânica em matéria orgânica - que vivem todos os outros viventes.

30 OLIVEIRA, Jelson. A transanimalidade do homem: uma premissa do Principio Responsabilidade. In: SANTOS, R.; OLIVEIRA, J.; ZANCANARO, L. (ed.). Ética para a civilização tecnológica: em diálogo com Hans Jonas. São Paulo: Centro Universitário São Camilo, 2011, p. 43.

31 JONAS, Hans. O principio vida: fundamentos para uma biologia filosófica. Tradução de Carlos Almeida Pereira. 2.ed. Petrópolis: Vozes, 2004, p. 13.

32 JONAS, Hans. Pensar sobre Dios y otros ensayos. Traducción de Ángela Ackermann. 2. ed. Barcelona: Herder, 2012, p. 21.

33 FROGNEUX, Nathalie. Uma liberdade responsável e descentrada em relação à natureza: leitura antropológica de Princípio Responsabilidade. Revista de Filosofia Aurora, Curitiba, v. 24, n. 35, 2012, p. 454

34 JONAS, Hans. Pensar sobre Dios y otros ensayos. Traducción de Ángela Ackermann. 2. ed. Barcelona: Herder, 2012, p. 20.
} 
inerentemente arriscada".,35

A vida busca manter constantemente sua existência precária e retardar seu desaparecimento. ${ }^{36}$ O ser vivo abre-se ao mundo a fim de não morrer. A sua liberdade é, portanto, o "exercício da autoafirmação no reino da pura fragilidade e da ameaça do meio"37 que nem sempre está disponivel à satisfação das necessidades vitais do organismo vivo. O organismo vive, portanto, em vista de uma finalidade, a saber, manter-se vivendo, sendo.

O horizonte da possibilidade de não-ser faz com que a vida esteja sempre suspensa sobre esse abismo, de tal forma que o organismo é dono de seu ser apenas de modo condicional e revogável. "A vida, por sua própria natureza é. portanto, um constante ato renovado de afirmação". ${ }^{38}$ Os graus ascendentes de liberdade são os modos pelos quais a vida se autoafirma com o objetivo de dizer não ao não-ser e tais graus assumem os perigos de uma abertura cada vez maior ao mundo-ambiente.

Tal liberdade marcada pela fragilidade da existência, traço localizado na base do orgânico, aparece, para o filósofo, em plena luz na existência animal. A autonomia em relação à natureza, isto é, um distanciamento em relação ao mundo enfrenta na vida animal uma existência mais precária e transitória que na vida da planta. Mobilidade, percepção e sentimento apontam para esse distanciamento entre a vida do animal e a vida da planta.

Apesar da mera excitabilidade já expressar a abertura ao mundo, o autor afirma que a referência real ao mundo "só surge com o desenvolvimento de sentidos específicos, de estruturas motoras definidas e de um sistema nervoso central"39. Ou seja, a existência animal inaugura o desenvolvimento do elemento da transcen- dência, uma vez que "fornece os inícios de um verdadeiro mundo objetivo".40

A mobilidade, no animal, é constituida como perseguição ou como fuga, já que se volta ou se afasta de um objeto desejado que não está imediatamente disponivel. A locomoção animal desenvolve então a percepção à distância, sendo que é o desejo que está na raiz da caça e o medo na raiz da fuga, elementos que sinalizam o início da vida emocional.

A mobilidade, segundo o autor, é aquilo que torna a diferença entre animal e planta visivel. Para a planta "o ambiente não é outra coisa senão o contexto imediato com o qual ocorrem os processos químicos de troca do metabolismo". ${ }^{41} \mathrm{~A}$ matéria está continuamente disponivel à planta, não possibilitando, consequentemente, que esse anseio tome a forma de um desejo. A existência animal é, ao contrário, caracterizada pela perda da imediatez de sua satisfação. A presença do objeto de seu desejo não é garantida e, além disso, é inconstante. A vida produz, assim, uma separação entre animal e ambiente:

\begin{abstract}
um ambiente que não se encontra mais em contato direto nem está de maneira imediata disponivel para suas necessidades metabólicas. A separação entre relação direta e relação mediata com o ambiente coincide com a separação entre planta e animal, devendo, pois, coincidir com a diferença entre suas formas de metabolismo. ${ }^{42}$
\end{abstract}

Há sempre uma distância entre o animal e seus objetos de desejo, enquanto para a planta o ambiente tem um significado diferente, a saber, o de constante ligação. A planta encontra-se integrada ao ambiente, diferente do animal, o que, consequentemente, gera o sentimento da falta e

\footnotetext{
35 HAUSKELLER, Michael. The ontological ethics of Hans Jonas. In: MEACHAM, D. (ed.). Medicine and Society, new perspectives in continental philosophy. [s.l.]: Springer, 2015, p. 43

36 PINSART, Marie-Genevieve. Jonas et la liberté. Dimensions théologiques, ontologiques, éthiques et politiques. Paris: Vrin, 2002, p. 97.

37 OLIVEIRA, Jelson. Compreender Hans Jonas. Petrópolis: Vozes, 2014, p. 65.

38 HAUSKELLER, Michael. The ontological ethics of Hans Jonas. In: MEACHAM, D. (ed.). Medicine and Society, new perspectives in continental philosophy. [s.l.]: Springer, 2015, p. 43

39 JONAS, Hans. O princípio vida: fundamentos para uma biologia filosófica. Tradução de Carlos Almeida Pereira. 2.ed. Petrópolis: Vozes 2004, p. 124.

40 JONAS, Hans. O principio vida: fundamentos para uma biologia filosófica. Tradução de Carlos Almeida Pereira. 2.ed. Petrópolis: Vozes, 2004, p. 124.

41 JONAS, Hans. O principio vida: fundamentos para uma biologia filosófica. Tradução de Carlos Almeida Pereira. 2.ed. Petrópolis: Vozes, 2004, p. 127.

42 JONAS, Hans. O principio vida: fundamentos para uma biologia filosófica. Tradução de Carlos Almeida Pereira. 2.ed. Petrópolis: Vozes, 2004, p. 127.
} 
do medo. É, no entanto, esse caráter mediato da vida animal que funda a mobilidade, a percepção e o sentimento como aquilo que constitui e diferencia o animal da planta.

O mundo é, para o animal, ao mesmo tempo, convidativo e ameaçador. ${ }^{43}$ Ao mesmo tempo em que cresce a liberdade aumenta também o risco da condição da existência animal que ao desejar não tem seu objeto imediatamente disponivel (falta) e pode não obter o êxito na empreitada de busca por satisfação (medo).

O animal é um ponto do processo em que um "eu" "mais pronunciado se confronta com um mundo mais diferenciado".44 Ou seja, o animal marca o fosso que se abre entre sujeito e objeto. Hans Jonas por meio de sua ontologia da vida busca mostrar como o caráter teleológico da vida, isto é, orientada por fins, possibilita pensar a transposição desse fosso nas formas de relação que a vida animal mantém com a vida da planta e, sobretudo, com a vida humana.

Sobre o plano ontológico, a ameba e o ser humano constituem, então, os limiares respectivos da liberação da matéria e do pensamento. A ameba assinala a separação entre a matéria e a forma, ao passo que a aparição do ser humano assinala a aparição de uma liberdade doravante ambivalente, porque reflexiva. Entre as duas, o animal manifesta uma subjetividade no mundo e uma liberdade de movimento, mas também um desejo. Fenomenologicamente, a animalidade constitui o momento pelo qual se manifesta a continuidade entre as formas mais simples e as mais complexas da vida, a saber o metabolismo que repousa sobre a dialética da afirmação de si por negação ao não-ser. Essa resposta incessante à ameaça do não-ser torna-se explícita quando o animal que é 'essencialmente um ser apaixonado' está distante do que pode satisfazer suas necessidades. ${ }^{45}$
Qual é, então, o lugar que o animal ocupa entre os organismos viventes mais simples (os unicelulares) e os organismos humanos que aparecem como a manifestação da liberdade afirmativa já presente no metabolismo? "A síndrome animal caracteriza para Jonas, de certa forma, o momento fenomenal de uma liberdade afirmativa". ${ }^{6} \mathrm{O}$ u seja, o animal prepara a partir da mobilidade, sentimento e percepção a liberdade afirmativa presente no ser humano. $O$ animal é a condição de possibilidade do aparecimento do humano, "enquanto titular de 'potencialidades transanimais' suscetiveis de ulterior desenvolvimento". O animal é a "forma vivente sem o qual o ser humano não poderia ter existido".47

A partir de sua biologia filosófica Jonas buscou pensar, então, a questão do lugar do animal na evolução da vida a partir da ideia de transanimalidade ${ }^{48}$ que "autoriza uma perspectiva de análise sob a qual o ser humano se vê como animal entre os animais e ao mesmo tempo distinto deles".49 No entanto, essa diferença não permite que as interpretações acerca da relação ser humano-animal, ser humano-natureza sejam marcadas por um abismo entre ambos. Pois, para o autor, "o ser humano participa do animal e inclusive fisicamente pertence ao reino animal".50 Por conseguinte, o homem, para Jonas, "não é mais um ente desligado das demais formas de vida e do reino orgânico em geral". ${ }^{1}$

\section{Problemas éticos perante a vida animal}

Hans Jonas denunciou o processo antropocêntrico e dualista da compreensão moderna da natureza, aquilo que ele nomeia de "a humanização

\footnotetext{
43 JONAS, Hans. O principio vida: fundamentos para uma biologia filosófica. Tradução de Carlos Almeida Pereira. 2.ed. Petrópolis: Vozes 2004, p. 129

44 JONAS, Hans. O principio vida: fundamentos para uma biologia filosófica. Tradução de Carlos Almeida Pereira. 2.ed. Petrópolis: Vozes, 2004, p. 131

45 FROGNEUX, Nathalie. Le syndrome animal chez Hans Jonas. In: BURGAT, Florence; ClOCAN, Cristian (ed.). Phénomenologie de la vie animale. Bucarest: Zeta Books, 2016, p. 247.

46 FROGNEUX, Nathalie. Le syndrome animal chez Hans Jonas. In: BURGAT, Florence; CIOCAN, Cristian (ed.). Phénomenologie de la vie animale. Bucarest: Zeta Books, 2016, p. 257

47 TIBALDEO, Roberto Franzini. Animal, transanimal e humano no pensamento de Hans Jonas. In: CARVALHO, H. B. A. de; OLIVEIRA, J. (ed.). Ética, técnica e responsabilidade. Curitiba, PR: CRV; Teresina, PI: EDUFPI, 2015, p. 46.

48 JONAS, Hans. Pensar sobre Dios y otros ensayos. Traducción de Ángela Ackermann. 2. ed. Barcelona: Herder, 2012, p. 27.

49 OLIVEIRA, Jelson. A transanimalidade do homem: uma premissa do Principio Responsabilidade. In: SANTOS, R.; OLIVEIRA, J.; ZANCANARO, L. (ed.). Ética para a civilização tecnológica: em diálogo com Hans Jonas. São Paulo: Centro Universitário São Camilo, 2011, p. 53.

50 JONAS, Hans. Pensar sobre Dios y otros ensayos. Traducción de Ángela Ackermann. 2. ed. Barcelona: Herder, 2012, p. 27.

51 OLIVEIRA, Jelson. A transanimalidade do homem: uma premissa do Principio Responsabilidade. In: SANTOS, R.; OLIVEIRA, J.; ZANCANARO, L. (ed.). Ética para a civilização tecnológica: em diálogo com Hans Jonas. São Paulo: Centro Universitário São Camilo, 2011, p. 43.
} 
da natureza"52 segundo a qual o ser humano não está submetido à natureza, mas, o contrário. Ela consiste, desse modo, em subjugar a natureza ao ser humano com o objetivo de explorá-la para as suas necessidades.

Podemos identificar um antropocentrismo radical nessa posição, uma vez que humanizar a natureza é transformá-la, ou melhor, reconstrui-la adequando-a aos desígnios humanos. Logo, "a natureza humanizada é a natureza alienada de si mesma".53 Jonas se coloca, por conseguinte, como crítico deste processo de humanização da natureza que, na verdade, não revela uma proximidade entre ambos. Diz o autor:

'Humanização' da natureza? Ao contrário, alienação não só de si própria, mas também dos homens. E mais ainda se passamos do exemplo vegetal para o animal, com as fábricas de criação de galinhas e ovos, que hoje abastecem os supermercados e diante das quais o galinheiro camponês, com os seus galos, mais pareceria um jardim zoológico! O aviltamento final de organismos dotados de sentido e de movimento, sensiveis e exuberantes, transformados em máquinas poedeiras e fornecedoras de carne. desprovidas de meio ambiente, encerradas por toda vida, artificialmente iluminadas e automaticamente alimentadas, não tem nada a ver com a natureza. Não seria o caso de se falar aí em 'abertura' da natureza e 'proximidade' com o homem. O mesmo se deveria dizer das prisões de engorda para a produção de carne de vaca, e assim por diante. Até o ato sexual foi substituido pelo processo de inseminação artificial. É assim que se mostra 'a reconstrução da natureza'in concreto e in praxi! 54

Como afirma Frogneux, seguindo Jonas, a vida dos animais submetidos ao processo de humanização não são mais vidas de animais. A vaca entregue à industrialização não tem mais uma vida de vaca, assim como as galinhas não têm mais uma vida de galinha. Confinamos os animais entregues à industrialização a uma sobrevivência condenada à produção. O reconhecimento de nosso passado animal não impediu a coisificação da vida animal, o que somado ao crescente poder da técnica conduz àquilo que Derrida chamou de "genocidios animais". 55

\section{Considerações finais}

Como afirma Hans Jonas, "chegou o tempo para a tarefa da antropologia filosófica voltar a refletir sobre o essencialmente transanimal no ser humano", sem com isto "negar sua animalidade".56 O retorno a essa problemática se justifica pelo fato de que as considerações filosóficas acerca do animal presentes na tradição metafísica ocidental são marcadas pela tentativa de esconder não apenas a dimensão animal do ser humano, mas também negligenciar a pergunta pelo animal.

Uma análise do ser animal como Jonas a pensa, amparada em uma ontologia que conduz à ética da responsabilidade, torna-se uma tarefa centraljá que a tradição metafísica ocidental representa uma forma de violência com respeito ao animal, a violência da negação teórica preparando e como que legitimando a violência ética da exploração técnica.

\section{Referências}

BIMBENET, Étienne. O animal que não sou mais. Tradução de Maurício José d'Escragnolle Cardoso. Curitiba: Ed. UFPR, 2014.

COCCIA, Emanuele. La vie des plantes: une métaphysique du mélange. Paris: Bibliothèque Rivages, 2016.

DERRIDA, J. O animal que logo sou. Tradução de Fábio. 2. ed. São Paulo: Editora Unesp, 2011.

FROGNEUX, Nathalie. Le syndrome animal chez Hans Jonas. In: BURGAT, Florence; CIOCAN, Cristian (ed.). Phénomenologie de la vie animale. Bucarest: Zeta Books, 2016.

FROGNEUX, Nathalie. Uma liberdade responsável e descentrada em relação à natureza: leitura antropológica de Principio Responsabilidade. Revista de Filosofia Aurora, Curitiba, v. 24, n. 35, p. 435-464, 2012. https:// doi.org/10.7213/revistadefilosofiaaurora.7513.

HAUSKELLER, Michael. The ontological ethics of Hans Jonas. In: MEACHAM, D. (ed.). Medicine and Society, new perspectives in continental philosophy. [s.l.]: Springer, 2015, p. 43.

\footnotetext{
52 JONAS, Hans. O princípio responsabilidade: ensaio de uma ética para a civilização tecnológica. Tradução de Marijane Lisboa e Luiz Barros Montez. Rio de Janeiro: Contraponto, 2006, p. 334.

53 JONAS, Hans. O principio responsabilidade: ensaio de uma ética para a civilização tecnológica. Tradução de Marijane Lisboa e Luiz Barros Montez. Rio de Janeiro: Contraponto, 2006, p. 334.

54 JONAS, Hans. O princípio responsabilidade: ensaio de uma ética para a civilização tecnológica. Tradução de Marijane Lisboa e Luiz Barros Montez. Rio de Janeiro: Contraponto, 2006, p. 336.

55 DERRIDA, J. O animal que logo sou. Tradução de Fábio. 2. ed. São Paulo: Editora Unesp, 2011, p. 52.

56 JONAS, Hans. Pensar sobre Dios y otros ensayos. Traducción de Ángela Ackermann. 2. ed. Barcelona: Herder, 2012, p. 29
} 
HEIDEGGER, Martin. Os conceitos fundamentais da metafisica: mundo, finitude, solidão. Tradução de Marco Antônio Casanova. Rio de Janeiro: Forense Universitária, 2003.

JONAS, Hans. Essais philosophiques: Du credo ancien à l'homme technologique. Paris: Vrin, 2013.

JONAS, Hans. O principio responsabilidade: ensaio de uma ética para a civilização tecnológica. Tradução de Marijane Lisboa e Luiz Barros Montez. Rio de Janeiro: Contraponto, 2006.

JONAS, Hans. O principio vida: fundamentos para uma biologia filosófica. Tradução de Carlos Almeida Pereira. 2.ed. Petrópolis: Vozes, 2004.

JONAS, Hans. Pensar sobre Dios y otros ensayos. Traducción de Ángela Ackermann. 2. ed. Barcelona: Herder, 2012

OLIVEIRA, Jelson. A transanimalidade do homem: uma premissa do Principio Responsabilidade. In: SANTOS, R.; OLIVEIRA, J.; ZANCANARO, L. (ed.). Ética para a civilização tecnológica: em diálogo com Hans Jonas. São Paulo: Centro Universitário São Camilo, 2011.

OLIVEIRA, Jelson. Compreender Hans Jonas. Petrópolis: Vozes, 2014.

PINSART, Marie-Genevieve. Jonas et la liberté.Dimensions théologiques, ontologiques, éthiques et politiques. Paris: Vrin, 2002.

TIBALDEO, Roberto Franzini. Animal, transanimal e humano no pensamento de Hans Jonas. In: CARVALHO, H. B. A. de; OLIVEIRA, J. (ed.). Ética, técnica e responsabilidade. Curitiba, PR: CRV; Teresina, PI: EDUFPI, 2015

VASCONCELOS, Thiago. Existência em exilio: a questão do niilismo na filosofia de Hans Jonas. 2017. 176 f. Dissertação (Mestrado) - Pontifícia Universidade Católica do Paraná, Curitiba, 2017.

Thiago Vinicius Rodrigues de Vasconcelos

Doutorando na Pontificia Universidade Católica do Paraná (PUCPR).

\section{Endereço para correspondência}

Thiago Vinicius Rodrigues de Vasconcelos

R. Imac. Conceição, 1155 - Prado Velho

Curitiba - PR

80215-901 